\title{
An E-Culture Environment for Common Citizens and Visually Impaired Individuals
}

\author{
Athanasios Drigas, Leyteris Koukianakis, and John Glentzes \\ NCSR 'Demokritos', \\ Institute of Informatics and Telecommunications, \\ Net Media Lab, \\ Agia Paraskevi, 153 10, Athens, Greece \\ $\{d r$, kouk, jglen\}@imm. demokritos.gr
}

\begin{abstract}
The integration of modern Information and Communication Technologies (ICTs) within the cultural domain creates what is commonly known as e-culture. The need to create an e-culture environment arose from the undeniable fact that the cultural heritage of a nation defines a nation and therefore should be disseminated to all, regardless of their location and their disability. This article discusses an e-culture portal, which presents to any interested users, information regarding a significant number of Greek and Cypriot museums and galleries as well as their exhibits. The e-culture environment offers user friendly navigation techniques and contemporary multimedia tools and services for the better presentation of the e-material to the users-visitors, paying particular attention to common citizens and especially to visually impaired individuals, in order to offer them equal access to cultural heritage information. This environment is an inter-disciplinary application, combining the ICTs, cultural and e-inclusion domains (electronic support for disabled people).
\end{abstract}

Keywords: e-culture, cultural heritage, ICT, digitization.

\section{Introduction}

The digitization of arts and culture has to do with the relationship between ICTs and the production and consumption of art and culture. By merging the above, the term eculture arises. In theory, e-culture comprises all processes of expression and reflection in the digital domain. That also includes, for instance, communities that share a certain lifestyle, interests or ideas [1], [2].

The term e-culture implied the need for a new type of policy. In fact, when it comes to cultural policy, developments surrounding ICT and digital media must be considered within a broad and integral perspective [3], [4], [5]. For this reason, the EU has already funded several projects. This program states that work will focus on "intelligent systems for dynamic access to and preservation of tangible and intangible cultural and scientific resources" [6].

New museums and galleries place a high value on accessibility and also on aesthetics issues. They are moving away from rows and rows of objects each fronted by a label containing limited and specific information. Strange then, that when these new 
museums start to digitize their collections they produce huge databases with modern agent-oriented methodologies [7], [8], [9], [10].

Moreover, the past years have seen the exploitation of multimedia techniques and lately the introduction of virtual reality methods to create new forms of presentation for museums' exhibitions. Virtual Reality can offer a number of advantages to museums, offering a way to overcome some common problems like the lack of space or the need of the visitors to interact with the exhibits [11], [12], [13], [14].

\section{Abstract Level Description}

The structure of the system content consists of the following five steps (Fig. 1):

- In the first step, a list of the existing museums and galleries categories in Greece and Cyprus appears. As a result of this categorization, the visitor can easily access the museum of his choice.

- The second step includes the listing and placing of museums/galleries, according to the corresponding categories. The total number of museums/galleries belonging to each category is satisfactory (having a mean term of 30) so that the uservisitor has a spherical and objective informing about every category

- During the third step, a study of every institutions' cultural content takes place, in order to show and present it in such a way that a user-visitor will not only obtain an integrated and representative view of a specific museum, but also he will ease his navigation, simultaneously making it more interesting

- Moving on, the cultural content which emerged from the previous step, is written and embedded into the whole system

- Finally, there is a thorough study of the system standards and outlines. The goal is to choose the appropriate techniques and technologies which will be used, so as to constitute the final product user-centered, user-friendly, and more importantly, to live up to the needs of disabled people and especially to those with visual disabilities in accord with the information and knowledge society strategies.

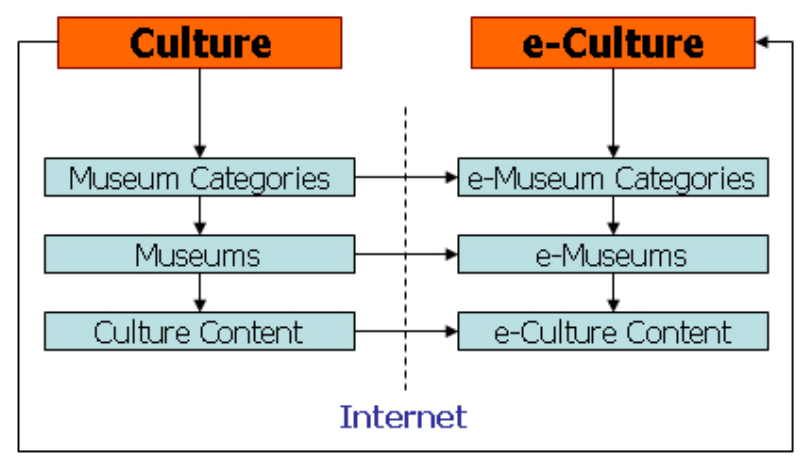

Fig. 1. System Structure 


\section{System Analysis}

This portal's opening page (Fig. 2) starts with a graphic and art visual application with the harmonious arrangement of lines and shapes, influenced by ancient Greece, in order to introduce the visitor from the beginning to its ambience. It has a simple but functional structure so that the visitor can easily navigate throughout the various categories of museums and galleries.

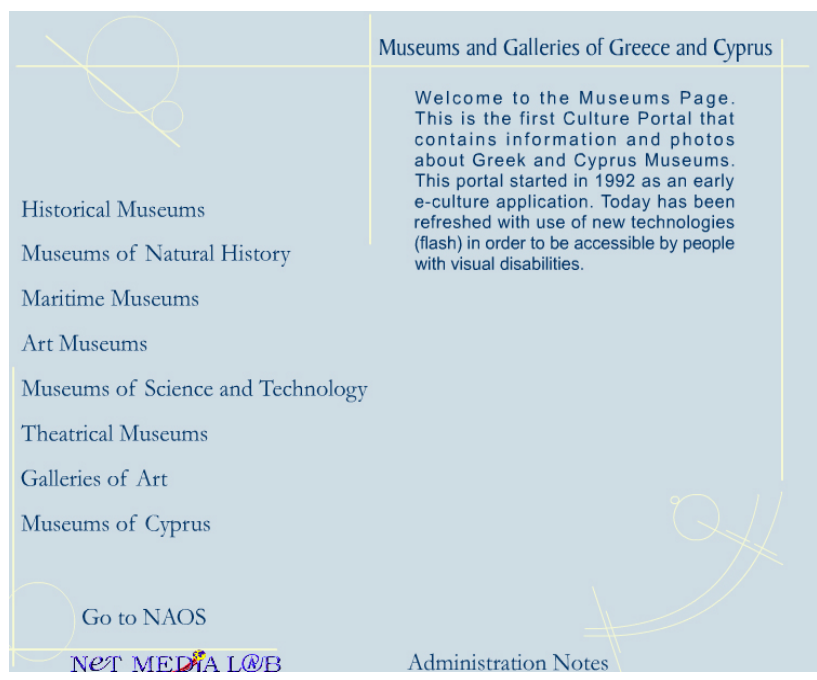

Fig. 2. Main page with graphic arts

After the search of the various museums/galleries categories in Greece and Cyprus, the following basic list was made:

- Historical Museums

- Museums of Natural History

- Maritime Museums

- Art Museums

- Museums of Science and Technology

- Theatrical Museums

- Galleries of Art

- Museums of Cyprus

The above categories are representative because they reflect the Hellenic cultural activities over the centuries and their aspects, such as history, tradition and customs.

At this point, the user-visitor has the option to choose one of the above categories in order to navigate through the corresponding museums/galleries. The choice of these institutions was made with the criterion to cover as much geographical space as possible in the Greek and Cypriot territories. The reason is because every region has its own cultural roots and uniqueness and consequently, a user-visitor can be informed about the whole of a region's culture even if this region is remote. 
In Fig. 3, part of the historical museums catalog is depicted. These museums exhibit the Greek history over the centuries, from the ancient years to the 20th century. For example, for the ancient Greek civilization some of them are: the museum of Atlantis, the Hippocratic museum of Kos etc, whereas for the modern era there are: the National Historical Museum, the Therissos Museum etc.

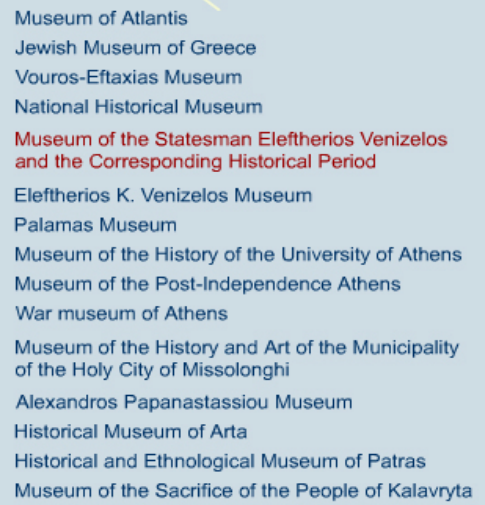

Fig. 3. List of Historical Museums

The final step of the navigation through the portal is the projection and presentation of a specific institutions' cultural content. This presentation consists of the following parameters, which emerged after a thorough study showing their connection to the rest of the system (Fig. 4). These are:

- Museum Address

- Museum Information

- Museum Photos

- Exhibits Images

With these elements of cultural content, the following can be achieved: the uservisitor can easily and quickly find the address and other data (telephone numbers, fax numbers etc.) of the institution, brief information about the institution itself (foundation, inauguration, founder, and exhibit pieces), a brief set of photographs showing the indoor and outdoor areas of the institution and finally representative images of the most important exhibits.

When a user has chosen a specific category, he can proceed to the next, which is the choice of appearance of the cultural content of a particular institution (Fig. 5).

With the use of Flash technology within the system, a user-visitor can enlarge the parameters Museum Address and Museum Information aiming at the cultural content to be legible for individuals with visual disabilities (Fig. 6). 


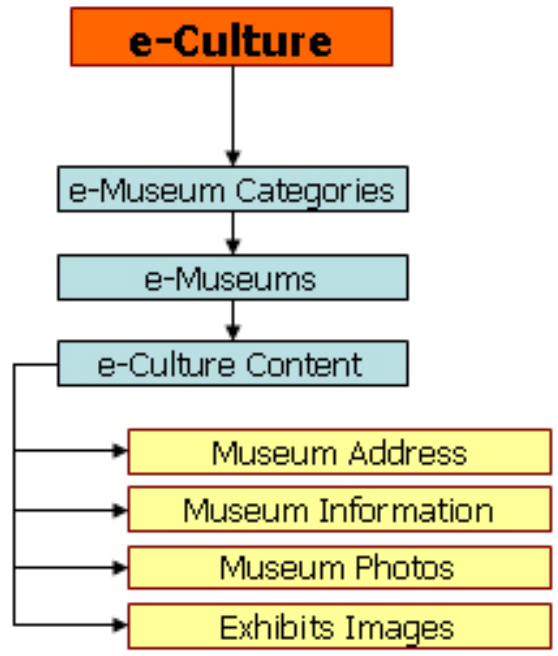

Fig. 4. E-culture content

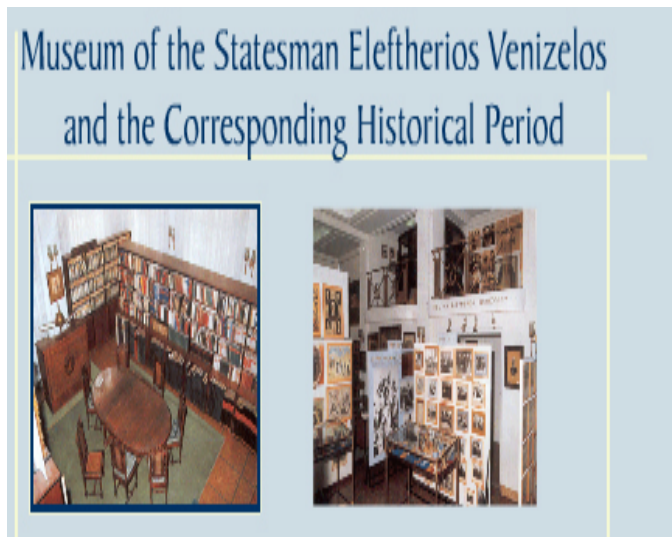

Fig. 5. Museum Photos

Choosing an image from the parameters Museum Photos and Exhibits Images, the visitor can view them in real size so as to have a clear picture of the exhibit or the institution areas.

To sum up, it can be said that the user-visitor has an integrated point of view of a museum and its exhibits as they are presented within the system. Of course, one cannot omit the fact that the knowledge-information presented within the environment is also available to people with visual disabilities, through the use of Flash technology, which is the backbone of the system, as it was previously mentioned. In this way, the system follows the «Information for All» logic and scheme as well as knowledge society strategies for user-centered systems [15]. 


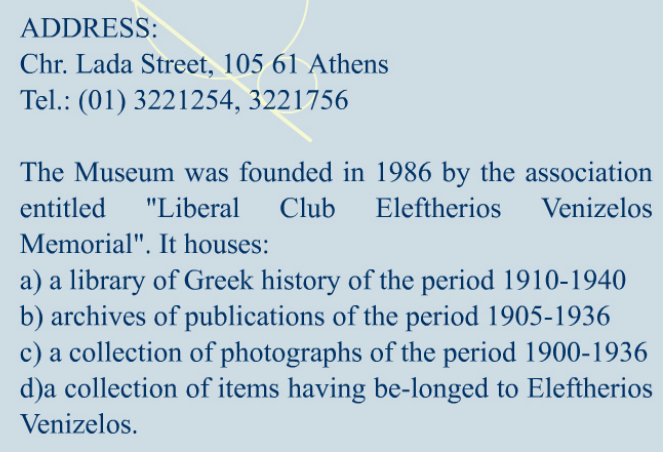

Fig. 6. Zoom of Museum Address \& Information

\section{Benefits}

The benefits of an e-culture system like the one described in this article and its importance to the information - knowledge society can be focused on the following:

- The diffusion of Greek civilization and generally of the Greek cultural heritage in a universal level. Additionally, this form of cultural heritage is at the disposal of every Greek citizen, that is, to the Greeks abroad and finally to foreign people who are eager to learn about Greek culture

- The cultural information is accessible from anyone, anywhere (even in remote places), at any time and with minimum cost [16]

- Saving and creating digital cultural content can lead to the preservation of cultural information during the course of time due to the constant physical degradation of monuments, statues etc. [15]

- Easy access to cultural information for disabled people complying with the usercentered strategy and the «equal access and knowledge for all» logic

- The projection of a country's cultural heritage can yield immediate results to the social sector of a country like the development of tourism, and in a wider sense the development of its economy [17], [18]

- The electronic projection of a country's cultural heritage is also a tool for education, study and research from scientists and students

- Finding new information out of existing information from other resources

- Creating new arts with the help of ICT tools, like graphic design, digital photography etc. As a result, new modern artists appear and simultaneously new professions and job vacancies are created [5],[19]

\section{Future Work}

The system presented is the first creative stage of an integrated e-culture system for navigation through Greek and Cypriot museums. The environment described in this 
article was created with the HTML programming language embedding at the same time the FLASH technology in order to achieve better visualization. The aforementioned technologies are compatible with every operational system as well as every Internet Browser. A future goal of the presented environment is the creation of an upto-date integrated e-culture system using modern techniques and technologies. Great importance will be given to the promotion and presentation of cultural information, due to the fact that there are new techniques and tools in the area of informatics such as:

- 3-tier architecture system

- Database systems

- Virtual Reality

- Digital Photography

- DVB Technology

- 3D games

- Learning environments

- Agents and avatars

- Mobile access to heritage information

- Location-based services

- New displays and human interfaces

- Virtual communities

All the above play an important role towards the creation of a user friendly eculture system, especially to children and the elderly who are not familiar with the use of a computer and its features [20].

\section{Conclusions}

From the detailed analysis carried out throughout this paper, the numerous advantages of the system that supports e-culture services became clear. Its main advantage is none other than the fact that it offers the pioneering experience for either a simple user-visitor or a scientist-researcher to combine two completely different worlds, the physical and online worlds, simultaneously.

This new e-culture challenge will drastically change the structures and relations that existed up to nowadays. Museum staff, volunteers and a wider public will require new skills to create, manage and maintain participatory and truly interactive digital applications. Museum people will need to understand experimental learning and the techniques of information management and multimedia creation. They will also need to draw on inputs from a wide range of disciplines, in the arts, sciences and humanities [5].

Culture is dynamic and creativity is at its core. Museums and galleries are centers for creativity. Their collections embody the accumulated cultural energy of contemporary and other times. They can be powerful catalysts for innovation. By making museums more accessible, a more creative society can be built. 


\section{References}

1. Netherlands Council for Culture: From ICT to E-Culture, Netherlands State Secretary for Education. Advisory Report on the Digitalization of Culture and the Implications for Cultural Policy, Culture and Science (2003)

2. Van der Ploeg, F.: Culture as Confrontation - Basic Assumptions on Culture Policy over the Period 2001-2004. The State Secretary for Education, Culture and Science of Netherlands (2002)

3. Wahler, A.: What's next for the e-Culture Community. In: International Workshop on European Cultural Heritage: RTD Challenges Ahead (2004)

4. Veltman, K.: Forecast of Application of IT in Cultural Heritage in the Next Decade. In: JRES, pp. 13-37 (2003)

5. A Netful Of Jewels - New Museums in the Learning Age. In: National Museum Directors' Conference (1999)

6. Digital Culture - Access to and Preservation of Cultural Heritage. European Commission (2004)

7. Durbin, G.: Where Lies the Added Value in Digital Cultural Heritage? In: Salzburg Research Symposium (2004)

8. Giunchiglia, F., Mylopoulos, J., Perini, A.: The Tropos Software Development Methodology: Processes, Models and Diagrams. In: Giunchiglia, F., Odell, J.J., Weiss, G. (eds.) AOSE 2002. LNCS, vol. 2585. Springer, Heidelberg (2003)

9. Trant, J., Bearman, D.: Educational Use of Museum Multimedia, the AMICO Library. The Art Libraries Journal 27 (2002)

10. Loran, M.: Use of Websites to Increase Access and Develop Audiences in Museums: Experiences in British National Museums. E-Journal of the Humanities and Philology Studies of the UOC 7 (2005)

11. Carreras, C.: Narrowcasting of Virtual Cultural Portals: The Cases of Barcelona's Botanic Gardens and the Boí Valley. E-Journal of the Humanities and Philology Studies of the UOC 7 (2005)

12. Charitos, D., Lepouras, G., Bourdakis, V., et al.: An Approach to Designing and Implementing Virtual Museums. In: Seventh UK VR-SIG Conference (2000)

13. Lepouras, G., Charitos, D., Vassilakis, K., Charissi, A., Halatsi, L.: Building a VRMuseum in a Museum. In: Virtual Reality International Conference (VRIC) (2001)

14. Almeida, P., Yokoi, S.: Interactive Character as a Virtual Tour Guide to an Online Museum Exhibition. In: Museums and the Web: An International Conference (2003)

15. Cultural and Linguistic Diversity in the Information Society. UNESCO, WSIS Publication Series (2003)

16. Mayer, H.: Knowledge and Presentation. In: International Workshop on European Cultural Heritage: RTD Challenges Ahead (2004)

17. Veltman, K.: Challenges for ICT/UCT Applications in Cultural Heritage. E-Journal of the Humanities and Philology Studies of the UOC 7 (2005)

18. Go, F., Lee, R., Russo, A.: E-Heritage in the Globalizing Society: Enabling Cross-Cultural Engagement through ICT. In: Information Technology and Tourism, pp. 55-68 (2003)

19. Drigas, A.: Electronic - Digital Culture (E-Culture). In: Information Society and Culture (2005)

20. Geser, G., Mulrenin, A.: Are Small Heritage Institutions Ready for E-Culture? In: ICHIMDigital Culture and Heritage (2004) 